\title{
P236: Effect of a prevention campaign on the prevalence of infections among patients in Belgian psychiatric hospitals: a dynamic prospective cohort study (2001-2010)
}

\author{
R Haenen ${ }^{1 *}$, S Vandenbroeck ${ }^{1,2}$, G Moens $^{1,2}$, A De Schrijver ${ }^{1,3}$, K Johannik $^{1}$, L Godderis ${ }^{1,2}$
}

From 2nd International Conference on Prevention and Infection Control (ICPIC 2013)

Geneva, Switzerland. 25-28 June 2013

\section{Introduction}

Infection control programs are crucial in reducing healthcare associated infections and their inherent costs. Few data on infection prevalence in psychiatry and effectiveness of prevention are available.

\section{Objectives}

In this study, we investigated in psychiatric institutions the evolution of 1) point prevalence of infections, infected patients, and antibiotics' use; 2) prevalence infection rates before and after a hand hygiene campaign.

\section{Methods}

Demographics, antibiotics' use, presence and type of infections were registered by an assessor using a standardized form. The criteria to determine the presence of an infection were based on the criteria of the Centers for Disease Control (1988).

\section{Results}

The overall infection, resp. infected patients prevalence was $18.9 \%$ and $16.5 \%$. The three most frequent infections were 1) skin or soft tissue $(38.7 \%), 2$ ) lower $(22.5 \%)$ and 3 ) upper respiratory tract infections (11.4\%). The prevalence of antibiotics' use was $2,7 \%$. The implementation of a hand hygiene campaign resulted in significant decreased prevalence of infected patients: $17.7 \%$ (95\% CI: 17.1-18.3) before versus $15.1 \%$ (95\% CI: 14.4 $15.7)$ in the 4-years after the implementation.
Antibiotics' use among infected patients diminished from $17.5 \%$ to $14.0 \%(\mathrm{p}<0.001)$.

\section{Conclusion}

These results are suggestive for a statistically and clinically significant effect of hand hygiene campaigns. Per 1000 patients/year, 37 infections and 26 infected patients have potentially been avoided.

\section{Disclosure of interest}

None declared.

\section{Author details}

'IDEWE, external service for prevention and protection at work, Heverlee, Belgium. ${ }^{2}$ Occupational, Environmental and Insurance Medicine, KU Leuven, Leuven, Belgium. ${ }^{3}$ Epidemiology and Social Medicine, UA, Antwerpen, Belgium.

\section{Published: 20 June 2013}

\section{doi:10.1186/2047-2994-2-S1-P236}

Cite this article as: Haenen et al:: P236: Effect of a prevention campaign on the prevalence of infections among patients in Belgian psychiatric hospitals: a dynamic prospective cohort study (2001-2010). Antimicrobial Resistance and Infection Control 2013 2(Suppl 1):P236.
IDEWE, external service for prevention and protection at work, Heverlee,

Belgium

Full list of author information is available at the end of the article 